\title{
Rubella Screening and Immunisation of Army Recruits
}

\author{
Lt Col C R McMillan
}

$M B, C h B, M S c, R A M C$

$H Q U K L F$

Dr J E M Watkeys

$\mathrm{MB}, \mathrm{BCh}, \mathrm{MSc}, \mathrm{DCH}$

King's Health District, London

SUMMARY: Copies of Rubella Screening reports for QARANC and WRAC personnel recruited between 1976 and 1980 were analysed. With the exception of WRAC servicewomen, insufficient numbers were screened. to be statistically significant until 1980 when $93.1 \%$ were successfully screened. 108 seronegative cases in 1980 were identified and a postal questionnaire was used to evaluate the efficiency of follow up immunisation pro- $\omega$ cedures. The results indicate that only $27.2 \%$ of susceptible cases were immunised because of a failure to identify this requirement by the units to which they were posted from recruit training. However, a review of vaccination schedules is likely to enable Rubella immunisation to be completed during basic training and the merits of widening the scope of immunisation are discussed.

\section{Introduction}

A survey of the Rubella antibody status of young adults by Clarke et $a^{1}$ produced evidence that the Rubella vaccination programme in the United Kingdom is having a significant impact on the immunological status of young females of childbearing age. The survey found that the incidence of seronegatives among the age groups offered Rubella vaccination at school was $4-7 \%$. The Queen Alexandra's Royal Army Nursing Corps (QARANC) and Womens Royal Army Corps (WRAC) recruit young women of childbearing age and must expect, therefore, that a proportion of these recruits will be seronegative. Accordingly, Rubella screening procedures are undertaken during recruit training courses with the object of identifying seronegative cases and offering them immunisation.

In 1979, Alexander and Slattery examined the effectiveness of Service policies for Rubella screening and their results suggested that screening was incomplete and follow up immunisation appeared inadequate. The objectives of this study therefore were to ascertain the proportion of QARANC and WRAC recruits screened and to evaluate the procedures for follow up immunisation of seronegative cases.

\section{Method}

Copies of Rubella screening reports up to and including those for 1980 were obtained from the Virology Department of the Royal Army Medical College and analysed by hand to identify serology status by rank and Corps.

The current duty stations of the 108 seronegatives in 1980 were obtained from the Manning and
Records Offices and postal questionnaires despatched to the relevant medical centres to obtain details of screening dates and results together with immunis tion dates, if recorded, from appropriate $F$ Med $4 s_{0}$ QARANC and WRAC Training Centres were visited to obtain details of administrative procedures.

\section{Results}

The percentage of seronegative recruits identified between 1976 and 1980 is shown in Table I. Wi⿺ the exception of WRAC servicewomen, insufficie numbers were successfully screened to be statistical significant until 1980. In that year a total of $2017 \overline{0}$ QARANC and WRAC recruits attended basic train- ٌ ing courses and 1877 of them were successfully $\stackrel{\mathbb{Q}}{\varrho}$ screened for Rubella. The details by rank and corps $\overrightarrow{\overrightarrow{0}}$ are shown in Table II. A total of 129 recruits $(6.4 \%) \frac{3}{3}$ were unsuccessfully screened. Of these no specimens were received in the laboratory for 100 , a further 17 contained insufficient blood, two were broken in $\exists$ transit and 10 produced an equivocal result. Bleeding was carried out at the training centres and the specimens despatched by Red Star Parcel Service to the Virology Department of the Royal Army Medical College on the same or following day. The haemagglutination inhibition test was carried out on Wednesdays and Thursdays of each week and the results returned to the training centres by first class mail despatched on Fridays. The median duration of interval from bleeding to despatch of $\frac{}{2}$ results was eight days with a standard deviation of $\frac{7}{2}$ two to eight days.

Of the 108 seronegative recruits $98(90.7 \%) \mathrm{F}_{\mathrm{N}}^{N}$ Med $4 \mathrm{~s}$ were examined and the results are shown in Table III, six recruits were discharged from the Army 
Table I

Percentage of Seronegative recruits between 1976 and 1980

1976

1977

1978 1979 1980

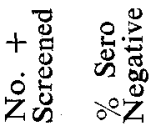

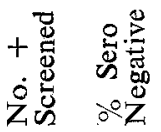

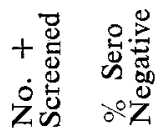

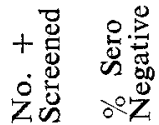

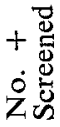

온

QARANC

Officers

Servicewomen

19

30

217

$\begin{array}{rr} & 20 \\ 5.5 & 189\end{array}$

10.0

$91 \quad 5.5$

WRAC

\begin{tabular}{lrrrrrrrrrr} 
Officers & 8 & 12.5 & 6 & 16.7 & & & 10 & 10.0 & 53 & 5.7 \\
Servicewomen & 672 & 5.2 & 1103 & 4.0 & 1162 & 3.3 & 1190 & 5.0 & 1360 & 5.9 \\
\hline TOTAL (All Ranks) & 680 & 5.3 & 1128 & 4.1 & 1409 & 3.5 & 1409 & 5.0 & 1877 & 5.7 \\
\hline
\end{tabular}

Note: Calendar years. + Number successfully screened.

Table II

Percentage of recruits screened in 1980

\begin{tabular}{lcccc}
\hline Corps and Rank & $\begin{array}{c}\text { No. of } \\
\text { recruits }\end{array}$ & $\begin{array}{c}\% \text { successfully } \\
\text { screened }\end{array}$ & $\begin{array}{c}\% \text { unsucessfully } \\
\text { screened }\end{array}$ & $\begin{array}{c}\% \text { not } \\
\text { screened }\end{array}$ \\
\hline QARANC & 110 & 82.7 & 7.3 & 10.0 \\
$\quad \begin{array}{l}\text { Officers } \\
\text { Servicewomen }\end{array}$ & 380 & 98.2 & 1.8 & 0 \\
WRAC & & & 5.4 & 0 \\
$\quad \begin{array}{l}\text { Officers } \\
\text { Servicewomen }\end{array}$ & 56 & 94.6 & 7.5 & 0.5 \\
\hline TOTALS & 1471 & 92.5 & 6.4 & 0 \\
\hline
\end{tabular}

Table III

Breakdown of $F$ Med 4 Results

\begin{tabular}{|c|c|c|c|c|c|c|}
\hline \multirow[b]{2}{*}{ Corps and Rank } & Number & \multicolumn{3}{|c|}{ Screening } & \multicolumn{2}{|c|}{ Immunisation } \\
\hline & Examined & $\begin{array}{l}\text { Number } \\
\text { Positive }\end{array}$ & $\begin{array}{l}\text { Number } \\
\text { Negative }\end{array}$ & $\begin{array}{l}\text { Number not } \\
\text { recorded }\end{array}$ & $\begin{array}{l}\text { Number } \\
\text { Immunised }\end{array}$ & $\begin{array}{c}\% \\
\text { Immunised }\end{array}$ \\
\hline
\end{tabular}

QARANC

Officers

Servicewomen

2

20

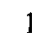

50.0

WRAC

Officers

(1)

18

1

10.0

Servicewomen

73

3

1

2

100.0

62

4

42.5

TOTAL (All Ranks)

98

9

84

5

37

37.8

Early discharge

$-6$

correction

Late immunisation

correction

$-12$

FINAL TOTAL

92

9

84

5

25

27.2

둥ㅇ

으

믐

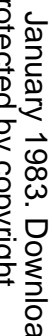

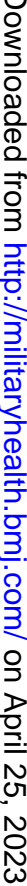


before completion of basic training. It can be argued, therefore, that there was insufficient time to immunise these recruits and this correction factor has been applied to Table III. An additional correction is applied for 12 cases that were immunised after receipt of the questionnaire. The final figures suggest that under current procedures, $72.8 \%$ of recruits susceptible to Rubella would not be immunised. Of those that were immunised, Figure $I$ indicates that $45.9 \%$ were protected by the 19 th week after screening and $83.9 \%$ by the 39 th week.

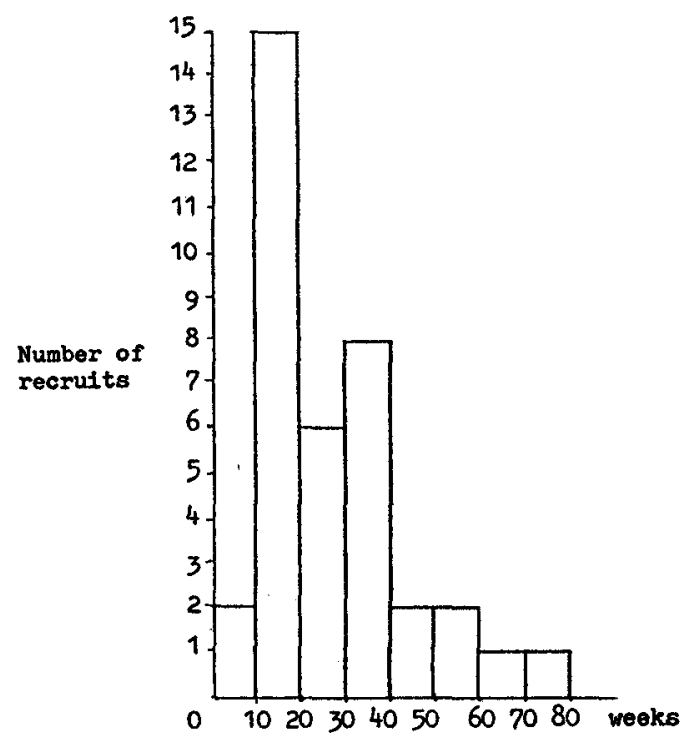

Interval - screening to immunisation

Fig. 1 Time taken to immunise 37 seronegative recruits

\section{Discussion}

It is a creditable performance to successfully screen $93.1 \%$ of recruits, but further improvement is possible. Alexander and Slattery ${ }^{2}$ identified the problems of obtaining sufficient blood at venepuncture particularly when priority is given to blood grouping. These problems cannot be overcome entirely but action is in hand at the Virology Department to telephone the details of unsuccessfully screened recruits to the appropriate training centres for immediate re-screening.

Clearly, the follow up immunisation of susceptible recruits is highly unsatisfactory mainly because there is insufficient time in the current recruit vaccination schedule at the training centres, and the requirement to immunise at the new unit medical centres following first posting is not being recognised. In addition $14.3 \%$ of the seronegative results reported by the laboratory are either not entered on the appropriate $F$ Med 4 or incorrectly transcribed as seronegative. With the cessation of smallpox vaccination in the Army in June 1981, it is likely that Rubella screening and immunisation of QARANC and WRAC recruits can be completed during basic training and the vaccination schedules are currently under review. Such a review may also consider the requirements to immunise other medical employees who are liable to have contact with pregnant patients. In an outbreak of Rubella among the staff of an ante-natal clinic in the USA, it was estimated that five employees exposed 200 women in the first 16 weeks of pregnancy to the disease ${ }^{3}$. The poor immunisation figures for the QARANC are particularly significant therefore, but doctors and ancillary staff are also involved and little or nothing is known of their serology status. However, Clarke et al $^{1}$ demonstrated that the proportion of young seronegative males in the UK is rising and this may well be reflected in male recruits to the RAMC. Such personnel frequently have contact with pregnant patients in the performance of their duties as doctors, male nurses reception clerks, orderlies and ambulance escortson They are therefore in a potential position to expose pregnant patients to Rubella infection. Alexandes and Slattery have recommended that all service women and RAMC personnel should be screened fo历 Rubella immunity and immunised where necessary These views are pertinent to the current review of the vaccination schedules in the Army and are aptlo summarised in an editorial ${ }^{4}$ which states thas "Routine Rubella vaccination of employees at ino creased risk of infection or involved with pregnant patients makes medical, epidemiologic, public health, financial and even legal sense."

\section{Acknowledgements}

The authors gratefully acknowledge the assistance provided by the staffs of the QARANC and WRAC Training Centres, Manning and Record Offices, Medical Centres and the Virology Department, RAM College. They would also like to thank Col I P Crawford for his encouragement with this study.

\section{REFERENCES}

1 Clarke $M$, et al. Effect of Rubella Vaccination Programme on Serological Status of Young Adults in United Kingdom. Lancet 1979; i: 1224-1226.

2 Alexander I, Slattery E M. Immunity to Rubella Amongst Service Personnel. J R Army Med Corps $1980 ; 126: 77-80$.

3 Exposure of Patients to Rubella by Medical Personnel. California Morbidity Mortality Weekly Rep 1978; $27: 123$.

4 Editorial. Rubella Vaccination of Hospital Employees. J Am Med Ass 1981; 245: 736-7. 